International Journal of Linguistics, Literature and Translation

ISSN: 2617-0299 (Online); ISSN: 2708-0099 (Print)

DOI: $10.32996 /$ ijllt

Journal Homepage: www.al-kindipublisher.com/index.php/ijltt

IJLLT

\title{
Practice and Reflection: Online English Teaching in University in China against the Outbreak of COVID-19
}

\author{
Yong LIANG \\ Ph.D., lecturer, School of Foreign Languages and Cultures, Xihua University, Chengdu, China \\ $\square$ Corresponding Author: Yong LIANG, E-mail: lukeliangnew@gmail.com
}

\begin{abstract}
ARTICLE INFORMATION ABSTRACT
Received: 17 September 2021

Accepted: 14 October 2021

Published: 31 October 2021

DOI: $10.32996 /$ ijllt.2021.4.10.26

\section{KEYWORDS}

English teaching, online learning, PBL, POA, Chinese learners

This study reviews, discusses and evaluates empirical university-level online English teaching in China that was largely influenced by the COVID-19. It introduces the design and procedure of the curriculum and explains the targets as well as the results of undergraduates' English courses. With PBL and POA teaching strategies, the findings of the study revealed that the teaching effects are close to the expectation compared with that of in-class teaching, and students' learning satisfaction is not reduced by way of online teaching. Online teaching mode in College English courses in China could be effective and productive through the cooperation of teachers and students, which sheds light on the teaching design and practice in the post-pandemic era.
\end{abstract}

\section{Introduction}

Since the 21st century, the rapid development of science and technology has had a great impact on university education. Teachers in Chinese universities are required to be equipped with medium-level computer skills before they obtain the teachers' certificate. With the guidance from the Ministry of Education and the support of established national network infrastructure, teachers were asked to quickly adapt to the dramatically-changed teaching situation after the outbreak of COVID-19. During that time, i.e. mainly the 2019-2020-2 semester in China, both teachers and students were trained to conduct online teaching unexpectedly.

In China, most students majoring in non-English majors in university spend much time in their major studies, leaving only 2 to 4 hours for English courses per week. Generally speaking, students' English foundation is weak, especially the oral ability, because the speaking capability is not a compulsory testing part for the college-entrance examination (the Gaokao). Students' speaking ability varies from region to region, and those from the western areas of China normally have fewer sources and chances to practice their oral English with native English-speaking people.

Because of a long-term absence of practical use of English, they may have a certain degree of timidity in English courses and even feel reluctant to practice English speaking after class, overlooking the cultural function of English learning. After entering the University in China, students realized that the College English course is compulsory for about one to two years, but some students in non-English majors only wish to pass the final test at the end of each semester, without much interest in active English learning, not to mention reading original English novels or cultivating the ability for intercultural critical thinking. Some students even claim that they only rely on guessing when answering questions in the listening part.

In addition, many employers mainly attach importance to the scores of writing, translation, reading, listening parts in the national College English Test (CET) band 4 or 6 . Thus, speaking ability is thus often paid less attention by both the employers and employees. In fact, without the score of oral English proficiency, students can still get the English certificate as long as they reach the qualified line, i.e., 425 out of the total score of 710 . As for the newly added oral proficiency test, some students said they had no confidence to attend. The acquisition of adequate listening and speaking ability is difficult, which requires learners to practice and learn constantly. In turn, it is also an important and difficult point in English teaching in China. The traditional teaching mode, such as learning vocabulary first, then text, grammar, and long and difficult sentences, has become less efficient to motivate students in

Copyright: (c) 2021 the Author(s). This article is an open access article distributed under the terms and conditions of the Creative Commons Attribution (CC-BY) 4.0 license (https://creativecommons.org/licenses/by/4.0/). Published by Al-Kindi Centre for Research and Development, London, United Kingdom. 
the "internet + " virtual world, which achieves relatively worse effect in helping students overcome the fear of difficulties and encouraging them to take the initiative in learning.

At present, some scholars have studied the cultivation of listening and speaking ability (Qi, 2015; Pan, 2015) and College English teaching theories (Wen 2012, 2018), but the study of online English teaching, particularly on students' listening and speaking ability (Zhang 2015), in Chinese universities after the outbreak of COVID-19 is still insufficient.

In the 2019-2020-2 semester, I taught a course titled "English for Academic Purposes", which was a required course for non-English majors in their second year of study. Prior to this semester, students were taught face-to-face in a classroom in the traditional way, but due to COVID-19, classes were held online that semester. Prior to taking this course, students have completed three semesters of college English, have earned 10 credits, and have completed 160 hours of study. This course is the last compulsory English course at the college level. Students will not take intensive college English classes in their third and fourth years.

Against this background, I have reflected on the teaching philosophy, teaching process, teaching methods, and teaching effectiveness of traditional face-to-face lectures and online Internet-based lectures in the context of the COVID-19 epidemic by comparing the teaching effectiveness of three College English teaching classes totaling about 150 undergraduate students in two semesters. The vast majority of the students have passed the College English Test Band 4 (CET-4), and more than half of the students have passed the CET-6 exam. In terms of English learning, students have developed adequate self-learning ability and acquired adequate oral and written communication skills, but their understanding and application of general academic English is still lacking and has not been systematically trained. In other words, prior to this course, it was difficult for students to have the opportunity to practice speaking and listening in English on academic topics, and they were unfamiliar with making academic presentations and writing academic articles in English. This course also serves to lay the foundation for students' future academic writing, publication, and international communication.

\section{Theoretical Basis}

\subsection{PBL Teaching Strategy}

Project-based Learning (PBL), as one of the student-oriented pedagogies, refers to the teaching process in which students are the main body, guided by the completion of project requirements, through the inspiration and guidance from the teacher. (Beckett and Slater 2005) The specific tasks are assigned to students, and teachers need to guide, supervise and evaluate the learning process of students, with the goal of cultivating and improving students' learning ability. Li and Du (2014), based on their experience in academic English teaching, discussed students' autonomous learning and ability training and found its applicability for students in a Chinese university.

Nowadays, in the background of online learning and big data network, students could obtain various learning materials before class in English learning, but they seldom could judge the importance and value of these "raw" materials and they often lacked the knowledge for effective learning. Especially in the acquisition of listening, speaking, and interpreting ability, students' selfcognition, cognitive differences, learning anxiety, and knowledge structure, to a large degree, are different from those under the framework of the traditional teaching model. By arousing students' initiatives, can teachers lead them to learn actively, to find problems and solve them, and to guide them to long-term self-learning? By establishing a dynamic interactive teaching mode, can instructors build a more efficient teaching scheme?

Liu and Zhong (2002) comprehensively introduced the definition, composition, and operation mode of PBL, which is taken as an exploratory teaching mode, and explored the localization application of PBL. In the process of teaching aided by PLB strategy, foreign language teachers in universities could focus on project-based curriculum design, teaching implementation and management, quality control, monitoring, and evaluation. Through sub-group task completion, simulation of project operation, and role play, for example, introducing ancient Chinese literati to foreign friends in an academic conference, could improve students' interests and cultural awareness in language learning. To clarify teaching objectives and ignite students' inner fire for active participation in the English-learning class is important. In order to improve the teaching effect of English learning, teachers could try to build a multi-dimensional, complete and efficient English teaching system and evaluation system, so as to meet the needs of English teaching for the cultivation of high-quality talents.

\subsection{Output-driven Hypothesis and Application}

Merrill Swain (1995, pp. 125-144) put forward the output hypothesis, focusing on the positive effects of output in learning and on the wash-back process of language learning, which is enlightening. Aiming at the application of output-driven hypothesis in College English teaching, Wen (2008) from Beijing Foreign Studies University pointed out that the hypothesis holds that output is more important than input in the development of foreign language ability. Wen (2013) focuses on mainly four aspects, including teaching objectives, curriculum system, teaching process, and methods, as well as key factors in evaluation, and puts forward the "double-subjectivity" (p. 19) teaching mode, which means both teacher and student need to participate actively in the process of learning. In this information age and uncertain learning environment after the COVID-19-caused turmoil, the channel for students 
to receive information and the way and demand for learning knowledge has changed dramatically. Based on the output-driven hypothesis, it is possible to explore a new teaching model by using some powerful interactive e-learning platforms. Thereafter, based on the characteristics of Chinese English learners, Wen (2018) proposed a production-oriented Approach (POA) based on the Output-driven hypothesis to further promote output-oriented foreign language learning and teaching strategies.

According to this English teaching model, it is suggested to adopt the empirical mode of comparative teaching between experimental class and parallel class, which is conducive to the test of teaching effectiveness and the realization of two important teaching objectives: (1) to highlight the cultivation of students' listening and speaking ability and enhance their self-confidence in oral English communication; (2) to create conditions for a better combination of professional knowledge and English capability, so as to cultivate students' ability to listen and speaking related to academic purposes. The consciousness of active learning can provide more assistance for students and bring a life-long learning habit to them, and they could apply what they have learned when they choose jobs or pursue further study.

This course requires students to complete online learning tasks in a project-based learning style, complete online exercises on the ICOURSE platform ${ }^{1}$, and submit an article of no less than 1,000 words related to the Artificial Intelligence (Al) topic at the end of the course. The topic of the article submitted by the students will be discussed in class by the instructor and students, and in the article, they should pay attention to the norms of an academic paper, cite relevant references reasonably and accurately, state the thesis argument clearly, and present it to the group members through a PPT presentation at the end of the term.

\section{The Methodology and Teaching Model} 3.1 The Philosophy of "Double-Subjectivity"

In the teaching process, this course adheres to the "Double-Subjectivity" (Student-Centered \& Teacher-Led) teaching philosophy, asking students to pre-study after class, report and answer questions in class, and thus forming the habit and atmosphere of active learning. According to the empirical teaching experience, teachers are suggested to strengthen the study of the latest education and teaching theory, pay attention to students' cognitive emotion, and students' knowledge foundation and individually academic needs. For example, by applying the strategy and widely absorbing traditional Chinese culture by reading Confucianism, Daoism, and classical works, teachers' teaching ideas and academic literacy could be improved during the teaching practice. Daoist "nonaction" philosophy (Legge 1891) resembles the emphasis on students' auto-learning strategy and the Confucian idea of benevolence and the principles in the Doctrine of the Mean (tr. Ku 2018) may also bring instructors much inspiration in teaching, such as paying special care to students who are temporarily left behind in learning, and adhering to the "Golden Mean" in teaching, i.e., caring for the general interests of the class. Moreover, teachers may further internalize these practical and applicable teaching theories, and improve their theoretical level in combination with students' actual and various learning needs.

Qin (2020) paid attention to cultural function in language learning and emphasized that traditional Chinese culture and ancient books should not be neglected in English writing course (i.e., another important output ability), who argued that Chinese culture learning could benefit the improvement of students' English writing ability, which also represents the instrumental and cultural function of foreign language learning. By incorporating elements of traditional Chinese culture into the English curriculum, students will be able to learn English for academic purposes with cross-cultural communication ability. This is beneficial for students to develop their thinking patterns.

Under the guidance of the teaching theory, by combing the history and changes of English teaching in the new era, the teaching models for listening, speaking and translation could be strengthened to meet the requirements of national college English teaching reform, as well as the new oral English assessment. At the same time, teachers are suggested to strengthen the cooperation of teaching teams and pay attention to the combination of professional and English knowledge. According to students' various interests and birthplaces, for example, teachers may invite students to introduce their local culture or famous historical figures to their classmates in English. In accordance with students' aptitude and under the academic learning atmosphere, teachers may encourage students to become leading and influential scholars in the future.

\subsection{Learner's Needs and Teaching Tools}

In the early stage of curriculum design, it is a necessary phase for teachers, from a comparative perspective, to collect relevant information about students' learning expectations, understand students' characteristics, including knowledge structure, learning attitude, and personality differences. For example, through questionnaire tools, such as the widely used online tool - Wenjuan xing [questionnaire star], and online instant chat groups, such as the group voting analysis in the app - Tencent QQ and so on, teachers could further summarize and classify students' learning objective and English level, and formulate a detailed curriculum teaching plan accordingly, in order to fully understand the real English learning ability of students.

According to the author's teaching experience and students' feedback, for example, Tiktok, a video-sharing app, is downloaded by a large number of Chinese college students. Many videos, uploaded by English-speaking users, are often used to explain the knowledge of daily life with bilingual subtitles, and students can also find English learning videos from it, such as the correct 
pronunciation of some international brands, campus tour in foreign countries, a summary of English-Chinese translation skills, the introduction of classic foreign films and music, etc. In the traditional English class, a lot of time is used to analyze the text grammar, explain sentence translation. It becomes more difficult for students to keep focused for a long time, especially for online and longdistance teaching, because, from the author's online teaching experience, the function of real-time supervision is limited and technical problems (such as low network speed) may sometimes arise. By understanding the learning needs of students and using the Internet platform, teachers can design the course content by project-based teaching methodology.

Combined with syllabus requirements and curriculum objectives, teachers can design multiple projects around a certain topic. Students could choose their own project and complete the requirements in groups in the forms of role play, oral speech or translation of materials between English and Chinese, and so on. These output-driven methods encourage and invite students to fully present their talents in their own ways, and the philosophy of cooperation in English learning, rather than individual competition, might be more easily accepted in China. For example, in this course, many students' majors are not related to computer science. For these students, it is difficult to write about Al at first. By implementing the PBL learning concept, students, in cooperation, learn through reading and gradually understand the definition, characteristics, and applications of Al in the practice of completing projects. Students studying medicine were interested in the application of Al in the medical field, students majoring in transportation were more concerned with the development of Al-based autonomous driving technology, while students in humanities discussed the flaws and ethics of Al technology in depth.

Teachers use the classroom and network platform to provide help for students, such as background knowledge, the correct use of related words, phrases, and sentence patterns. The "student-centered" model does not mean that everything is left to students to explore. Because students are limited in relevant knowledge to a certain extent, even if they collect a large amount of information on the Internet, they may not be able to find a research question and they may lack scientific research theories and methods. After the completion of projects, teachers need to collect and analyze these outcomes after the deadline, so that the teachers can put forward evaluation and offer targeted opinions, avoiding simple comments or just grade evaluation. Students can get specific advice so that they can better maintain their enthusiasm for learning.

In addition, online mutual evaluation among students could be done in the class. For example, in the 2019-2020-2 semester, my colleagues and I often use Chinese online teaching software, such as Tencent Classroom, Tencent Meeting, Ketangpai [A+ Classroom], etc., to conduct peer evaluation, real-time dialogue, class presentations (see fig. 1) among students. It needs to be noted that at the beginning of the online teaching, both teachers and students are somehow unwilling to have an online face-toface dialogue in my course, and participants sometimes will post their pictures on the cover page of their PowerPoint slide when having a class presentation, instead of talking with the camera on, which, I believe, is understandable and acceptable in my course. From my observation, it also brings some benefits to a certain degree in language learning for less-skilled learners. In order to avoid students' perfunctory evaluation, teachers could list some specific requirements: for example, students have to list both advantages and disadvantages, offer at least one suggestion for others, and summarize the evaluation results in their own words.

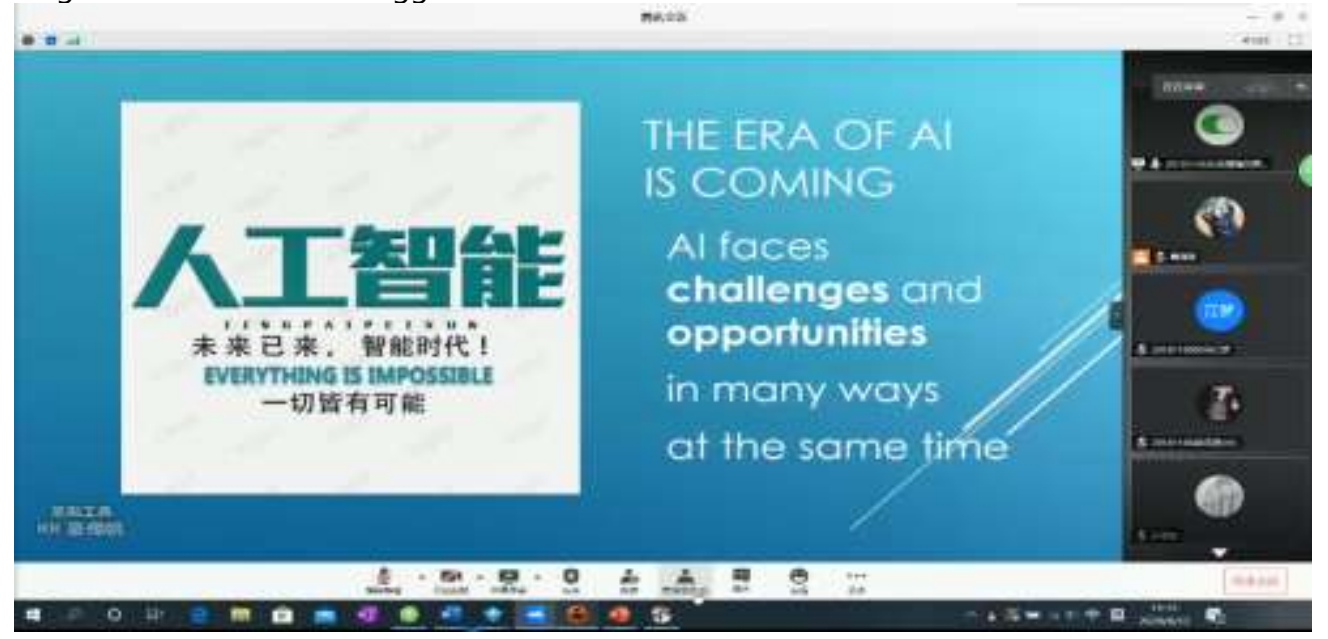

Fig. 1 Students' English Academic Presentation during the English Class at Tencent Meeting on June 12, 2020

\subsection{Aiming at Student's Output Capability}

Based on the university types, such as technological universities, teachers' universities, comprehensive and research-oriented universities, application-oriented universities, universities specialized in foreign studies, and other areas, teachers may have distinct teaching methods because of students' majors and learning objectives. As for the traditional Chinese culture in English classes in 
different universities, teachers could find a combination point with their university characteristics (see the example in my class, fig. 2). For example, teachers in technological universities in China may offer students English learning materials by asking them to finish some English-Chinese translation of non-literary Chinese works or read relevant research articles (Liang, 2019; Liang and Chang, 2020), such as early chemical technology and the idea of life-nourishing in China (Needham, 1974), or techniques of papermaking and printing in ancient China (see Tsien, 1985). Ma (2019) pointed out that English teaching needs to be filled with the content of Chinese traditional cultural essence so as to cultivate students' cross-cultural communication ability and help them to adapt to the globalization of the economy.

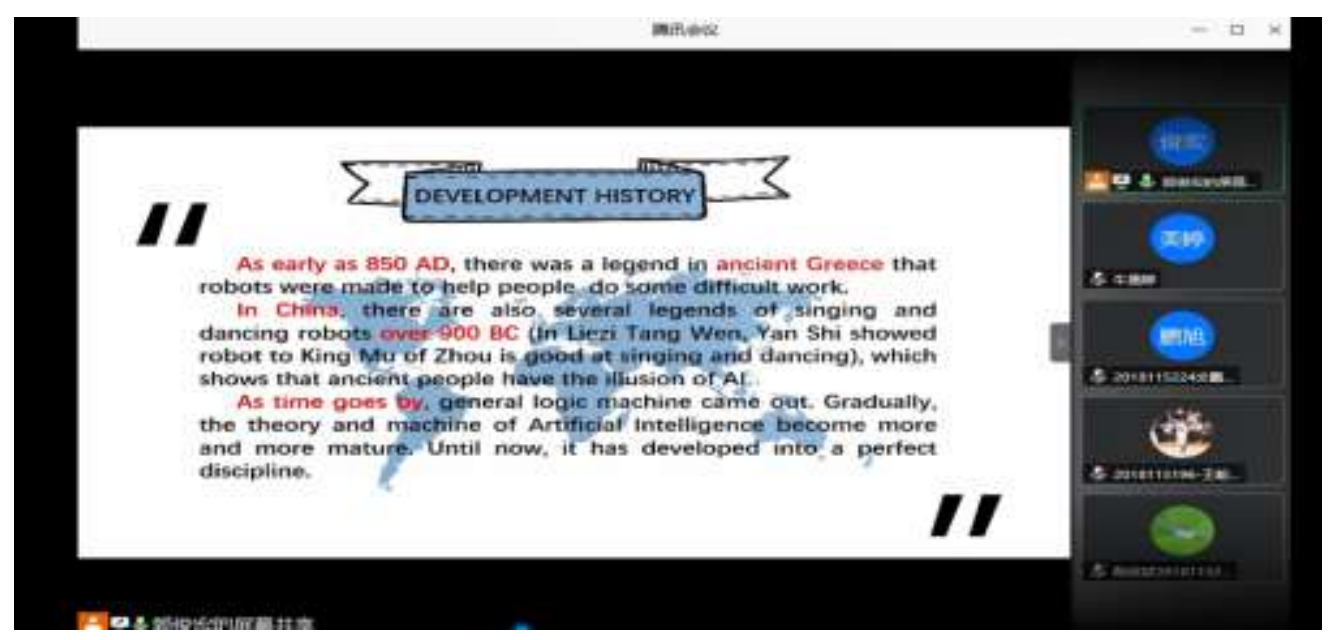

Fig.2 Students' English Report from a Contrastive Perspective on the Topic of Al on June 8, 2020

Under the theories of output-oriented strategy, teaching methods are consistent with the student's practical ability to use English. In 2020, due to the huge impact of COVID-19, teachers in Chinese universities widely used online learning platforms and resources, such as Chaoxing [Superstar] application, large MOOC platform for Chinese universities ${ }^{1}$, MOOC platform for foreign language learning(2), NetEase open class and other video sharing platforms, etc. Teachers integrated teaching resources and refreshed themselves with new teaching means and techniques, targeting to bring students substantial learning materials and effective learning results. These online videos and online discussions all need to be done after class, and students' output ability is enhanced through the flipped-classroom teaching method and the PBL strategies during the process. For example, the students could be divided into groups first, and the teacher could require them, if they major in media and communications, to shoot a short video to introduce ancient Chinese technology or great inventions in English with bilingual subtitles. During the process, teacher is responsible for reviewing the materials integrated by the students and answering the language problems they encounter. In this collaborative learning process, members are required to have a clear understanding of their task's first-hand requirements and make preparations based on first-hand investigation. Students need to take the initiative to list the problems they encounter, while teachers can summarize the problems or knowledge mistakes that students are not aware of during the project. After the completion of the project, teachers invite students to share the outcomes in the class and give them feedback and suggestions. Now teachers can use the network platforms, e.g. English composition-writing platform provided by Pigai(3), to collect students' homework and rate them with the assistance of linguistic corpus, providing a specific evaluation for each group or individual, so as to give targeted feedback to every language learner.

\section{Further Discussion}

The general English teaching mode in colleges and universities in China is facing new challenges, particularly in the post-COVID19 era. On the one hand, it is necessary to strengthen the learning of teaching software and platform operation (Fang and Warschauer 2004); on the other hand, teachers need to, regardless of their age, focus on how to realize network teaching more efficiently, create the same or similar effect as real classroom teaching by seizing students' attention.

Teaching methods such as live broadcasting and video sharing were widely used, and more online teaching platforms were developed and improved. Online listening and speaking are the main media for information exchange between teachers and students, which brings challenges for foreign language teachers, as face-to-face communication and timely feedback are highly needed in language learning. Teachers could pay more attention to the teaching process, improve the teaching effect by clarifying the teaching objectives of the course and assigning study tasks before the class. In the actual teaching process, teachers are suggested to enrich teaching resources, rely on multimedia, the Internet, and other multimodal teaching means, so as to reflect the requirements of the new era for educational reform and innovation. Thus, it can enhance teachers' ability in the combination 
of teaching theory and practice by focusing on students' output ability in English learning. With the insistence of strengthening input from both linguistic and cultural perspectives, students' learning motivation and production will be boosted.

English comprehensive ability, especially e.g. one's output capability -- speaking and interpreting, is of great importance to college students in non-English majors, because the job markets favor those who obtained certificates of English Proficiency. Besides, in industries like foreign trade, exhibition, and marketing, it is a common practice to translate relevant materials into foreign languages (mainly into English) and communicate with international experts. The importance of English listening and speaking cannot be overemphasized. In order to enable students to have practical English listening, speaking, and interpreting abilities and help students communicate with international co-workers in the workplace, it is necessary to explore a teaching mode that conforms to the characteristics of the times and students' professional requirements.

Therefore, regarding the teaching methods for non-English major students in Chinese universities, it is suggested that instructors need to fully consider the characteristics of their home university and students' English foundation so as to better explore a more practical and effective listening and speaking teaching model. They could integrate blended learning into the teaching process and develop students' learning capability by output-driven targets. What's more, teachers may purposefully blend local traditional culture into English learning. Thus, students may have real-life experience and relevant background knowledge to communicate with classmates in depth in a foreign language. Applying the strategy of PBL and POA could be an effective way in teaching planning, which can be, in turn, further explored and innovated in teaching practice based on the local culture.

\section{Conclusion}

The paper discussed the current English teaching situation and commonly used methods in college English classes, and it applied the theories and strategies of PBL and POA in English teaching for students in the university in China. It finds out that students' interests and impetus could be strengthened by asking them to complete tasks one by one during the semester, and students' awareness of cultural differences was improved after the introduction of traditional Chinese culture in English teaching. The paper argues that with a deeper understanding of their indigenous culture, especially traditional cultural essence, foreign language learners could benefit from the process of accumulating those cultural capitals, and their awareness of cultural identity will be increased.

In summary, the formulation of a teaching plan needs to be as close as possible to the learning needs of students, and combine the process evaluation with the overall evaluation. Teachers' comprehensive ability, including the understanding of their own culture, is of vital importance in language teaching. When choosing digital resources, users, both teachers, and students need to conform to certain social norms, avoiding unfavorable consequences in teaching and learning. For the teaching planning, teachers are suggested to constantly update the design, optimize the teaching content, and make periodic summaries during the process so as to achieve a satisfactory teaching effect. By introducing the online college English teaching experience and results in China during the COVID-19, it suggests that a blended learning mode in language teaching in the post-pandemic era is highly needed.

In this study, the number of subjects in this study is still limited, and qualitative research is still lacking. The subjects of study are only second-year non-English-major university undergraduates, and its scope can be further extended to graduate students as well as English majors. In addition to the results of course examinations and course papers written by students, questionnaires, individual interviews, and group discussions can also be conducted to investigate the effects of foreign language teaching in the post-epidemic era through qualitative analysis.

\section{Notes:}

(1) See one of the widely-known websites in universities in China that provides thousands of MOOCs built by the Higher Education Press in Beijing: URL=https://www.icourse163.org/.

(2) See the website built by Foreign Language Teaching and Research Press in Beijing: URL=http://moocs.unipus.cn/.

(3) The website is an online system that can automatically correct English compositions by computer, which is developed by an information company in Beijing, see URL=http://www.pigai.org/.

Funding: 四川省翻译协会.复旦大学出版社翻译理论与实践专项科研课题 [Translation Theory and Practice Project funded by Sichuan Translation Association and Fudan University Press] (No. YX2020014). 
Competing Interests: The author declares that there are no conflicts of interest regarding the publication of this paper.

\section{References}

[1] Beckett, G. H., \& Slater, T. (2005). The Project Framework: A Tool for Language, Content, and Skills Integration. ELT Journal, 59(2), 108-116.

[2] Fang, X., \& Warschauer, M. (2004). Technology and Curriculum Reform in China: A Case Study. TESOL Quarterly, (38): 301-323.

[3] Ku, H. (2018). The Conduct of Life, or the Universal Order of Confucius: A Translation of One of the Four Confucian Books, Hitherto Known asthe Doctrine of the Mean (Classic Reprint). London: Forgotten Books.

[4] Legge, J. (1891). The Texts of Taoism. Part I: The Tao The King, The Writings of Kwang Ze Books I-XVII, in The Sacred Books of China, Oxford: Oxford University Press.

[5] Li, L. and Du, J. (2014). 大学英语分科教学背景下学术英语PBL教学模式研究[Research on PBL Teaching Mode of Academic English under the Background of College English Subject Teaching]. Foreign Language Education, (5): 55-58.

[6] Liang, Y. (2019). Cross-cultural Travelling of Daode jing in the U.S. and Its Filtering and Variation. International Journal of Language and Literature, 7(1): 149-155.

[7] Liang, Y., \& Chang, S. (2020). Translating Technology and Culture: Analysis of Translation of Non-literary Chinese Texts in Science and Civilisation in China. International Journal of Linguistics, Literature, and Translation, 3(4): 99-108.

[8] Liu, J., \& Zhong, Z. (2002). 基于项目的学习(PBL)模式研究[Research on PBL model]. Studies in Foreign Education, (11): 18-22.

[9] Ma, H. (2018). 将中国传统文化融入英语教学势在必行[An Imperative Move to Integrate Chinese Traditional Culture into English Teaching]. Journal of the Chinese Society of Education, (10): 107.

[10] Needham, J. (1974). Science and Civilisation in China. Vol. V. Chemistry and Chemical Technology. Part 2. Spagyric Discovery and Invention: Magisteries of Gold and Immortality. With the collaboration of Lu, Gwei-djen. Cambridge: Cambridge University Press.

[11] Pan, H. (2015). 基于输出驱动假设的研究生公共英语--以吉林大学直博研究生公共英语教学为例[English Teaching for Non-English Majors Based on the Output-driven Hypothesis: a Case Study of Graduate Students in Jilin University]. Foreign Languages in China, (5): 73-79.

[12] Qi, P. (2015). 输出驱动下大学生听说实践能力培养的实证研究[An Empirical Study on the Cultivation of College Students' Listening and Speaking Ability with Output-driven Theory]. Foreign Language Research, (6): 132-135.

[13] Qin, Y. (2020). 中国传统文化典籍在英语写作类教学中的实践研究[A Practical Study of Chinese Traditional Cultural Classics in English Writing Teaching]. Education Research, (3): 3-4.

[14] Swain, M. (1995). Three Functions of Output in Second Language Learning. In: Cook, G., Seidlhofer, B.(Eds.), Principle and Practice in Applied Linguistics: Studies in Honour of H.G. Widdowson. Oxford: Oxford University Press.

[15] Tsien, T. (1985). Science and Civilisation in China. Vol. V. Chemistry and Chemical Technology. Part 1. Paper and Printing. Cambridge: Cambridge University Press.

[16] Wen, Q. (2008). 输出驱动假设与英语专业技能课程改革[Output-driven Hypothesis and Curriculum Reform of English Major]. Foreign Language World, (2): 2-8.

[17] Wen, Q. (2012) Teaching English as an International Language in Mainland China. In: Kirkpatrick A., Sussex R. (eds) English as an International Language in Asia: Implications for Language Education. Multilingual Education, vol 1. Springer, Dordrecht. https://doi.org/10.1007/978-94-007-4578-0_6

[18] Wen, Q. (2013). 输出驱动假设在大学英语教学中的应用:思考与建议[Application of Output-driven Hypothesis in College English Teaching: Reflections and Suggestions]. Foreign Language World, (6): 14-22.

[19] Wen, Q. (2018). The production-oriented approach to teaching university students English in China. Language Teaching, 51(4): 526-540. doi:10.1017/S026144481600001X

[20] Zhang, Y. (2015). Project-Based Learning in Chinese College English Listening and Speaking Course: From Theory to Practice. Canadian Social Science, 11(9): 40-44. 